\title{
Caffeoylquinic acid derivatives rich extract from Gnaphalium pensylvanicum willd. Ameliorates hyperuricemia and acute gouty arthritis in animal model
}

\author{
Yan Jiang ${ }^{1}$, Yan Lin², Yi-Juan Hü ${ }^{3}$ Xiao-Jun Song ${ }^{1}$, Hong-Hua Pan² and Hong-Jian Zhang ${ }^{3 *}$
}

\begin{abstract}
Background: The Gnaphalium pensylvanicum willd. is used in China as a folk medicine to treat anti-inflammatory, cough and rheumatism arthritis. The aim of this study was to evaluate the potential of the extract of $G$. pensylvanicum to treat hyperuricemia and acute gouty arthritis in animal model.

Methods: G. pensylvanicum extract was evaluated in an experimental model with potassium oxonate (PO) induced hyperuricemia in mice which was used to evaluate anti-hyperuricemia activity and xanthine oxidase $(\mathrm{XO})$ inhibition. Therapies for acute gouty arthritis was also investigated on monosodium urate (MSU) crystal induced paw edema model.

Results: G. pensylvanicum extract showed activity in reducing serum uric acid (Sur) through effect renal glucose transporter 9 (GLUT9), organic anion transporter 1 (OAT1) and urate transporter 1 (URAT1) mainly and inhibited $X O$ activity in vivo of mice with PO induced hyperuricemia. The extract of $G$. pensylvanicum also showed significant anti-inflammatory activity and reduced the paw swelling on MSU crystal-induced paw edema model. Meanwhile, 13 caffeoylquinic acid derivatives and 1 flavone were identified by UPLC-ESI-MS/MS as the main active component of G. pensylvanicum.
\end{abstract}

Conclusions: The extract of G. pensylvanicum showed significant effect on evaluated models and therefore may be active agents for the treatment of hyperuricemia and acute gouty arthritis.

Keywords: Gnaphalium pensylvanicum Willd., Caffeoylquinic acid derivatives, Hyperuricemia, Acute gouty arthritis, Xanthine oxidase, Pro-inflammatory cytokines

\section{Background}

Hyperuricemia is characterized by the high level of uric acid (UA) in blood, which may derive from the increase in purine metabolism and impairment of renal excretion of UA. Moreover, hyperuricemia is a key causal factor for the development of gout and many other diseases such as cardiovascular and renal diseases, hypertension and metabolic syndrome, etc. [1]. The terminal product of purine nucleotides degradation is UA. Xanthine

\footnotetext{
* Correspondence: jian871211@sina.com

${ }^{3}$ Key Laboratory of Research and Development of Chinese Medicine of Zhejiang Province, Zhejiang Academy of Traditional Chinese Medicine, 132 Tianmushan Road, Hangzhou 310007, China

Full list of author information is available at the end of the article
}

oxidase in liver is the key enzyme which catalyzes production of UA, and urate transport proteins in renal are the main transporters for UA clearance $[2,3]$. In addition, the crystallization of uric acid crystal within joints and tissues can drive an inflammatory response, therefore, the goal of the clinical treatment of gout is to reduce the Sur level and inflammatory response [4].

Impaired renal excretion of UA rather than UA overproduction was considered to be the major cause of hyperuricemia. Urate transport-related proteins, such as organic anion transporters involved in renal urate excretion and reabsorption, play a key role in maintaining urate homeostasis. Renal tubular handling of UA is dependent on urate transporters such as 
URAT1, GLUT9 and OAT1. URAT1, which is located in the brush border membrane of the renal tubular epithelial cell is responsible for reabsorption of urate transporter. This protein is encoded by the SLC22A12 gene, which is a genetic risk factor for inducing hyperuricemia [5]. GLUT9 (encoded by the SLC2A9 gene) was found to be a new target for the treatment of hyperuricemia as a high-capacity urate transporter [6]. In addition, the member of organic anion transporter 1 (OAT1, SLC22A6) distributed at the basolateral membrane contribute to renal urate secretion by mediating urate transport across cell membranes in renal proximal tubules [7]. These results suggest that URAT1, OAT1 and GLUT9 might play important roles in regulating urate excretion, and infecting the hyperuricemia. Thus, these urate transporters have proved to be very important targets for hypouricemia drug discovery [5-8].

Gnaphalium pensylvanicum willd. is an annual herbaceous plant and widely distributed in many regions of China. It has been used as a folk medicine for the relief of anti-inflammatory, cough and rheumatism arthritis [9]. Our previous study demonstrated that G. pensylvanicum extract (GPE) possess many caffeoylquinic acid derivatives and showed potent inhibitory activity against $\mathrm{XO}$ in vitro. Meanwhile, caffeoylquinic acid derivatives had been report that they showed potential antihuperuricemia and anti-gouty arthritis effect [10-13]. In addition, previous pharmacology works on various species of the Gnaphalium genus and its components possess XO inhibitory activity, showed significantly antihyperuricemia and anti-gouty arthritis [14-16]. Thus, further studies are needed to clarify the exact mechanisms of GPE in improving hyperuricemia and gout. Here, we assessed the effects of GPE with respect to its possible mechanisms by determining the XO, Sur, interleukin-1 $\beta$ (IL-1 $\beta$ ), tumor necrosis factor- $\alpha$ (TNF- $\alpha$ ), and the expression level of mUART1, mOAT1 and mGLUT9 in renal were also carried out to comprehensively study the mechanism of G. pensylvanicum against hyperuricemia and gout.

\section{Methods}

\section{Chemicals and reagents}

Potassium oxonate, allopurinol and uric acid were purchased from Sigma-Aldrich Chemical Company. Colchicine tablets (each tablet contains colchicine in a dosage of $0.5 \mathrm{mg}$ ) were purchased from Kunming Pharmaceutical Co., Ltd. (Yunnan, China). Commercial kit used for determining uric acid and $\mathrm{XO}$ activity were obtained from the Jiancheng Institute of Biotechnology (Nanjing, China). Enzyme-linked immunosorbent assay (ELISA) kits for IL- $1 \beta$ and TNF- $\alpha$ assay were purchased from Assay R\&D Systems. All other reagents used were standard laboratory reagents of analytical grade and were purchased locally. Antibodies against URATl, GLUT9, OAT1 and $\beta$-actin were purchased from ProteinTech Group (Chicago, IL), Abcam Inc. (Cambridge, MA, USA), and Santa Cruz Biotechnology (USA). Polyvinylidene fluoride (PVDF) membrane was purchased from Merck (Germany). Tissue Protein Extraction Kit was purchased from KeyGEN Biotech. CO., Ltd. (Nanjing, China). Enhanced bicinchoninic acid (BCA) protein assay kit was purchased from Tiangen Biotech (China). Monosodium urate (MSU) crystals were prepared according to the previously described method [17]. Approximately $1 \mathrm{~g}$ of uric acid was dissolved and heated in $200 \mathrm{~mL}$ of $\mathrm{H}_{2} \mathrm{O}$ with $6 \mathrm{~mL} \mathrm{NaOH}(1 \mathrm{~N})$, adjusted to $\mathrm{pH} 8.9$, cooled overnight at $4{ }^{\circ} \mathrm{C}$, washed, and dried. Needle-like crystals were recovered and were suspended in sterile saline and Twain $80(20 \mathrm{mg} / \mathrm{mL})$.

\section{Plant material}

Gnaphalium pensylvanicum willd. Was collected from Yuhuan by Xi-Biao Zhang, Zhejiang province, PR China in October 2015. It was identified by Licensed Pharmacist Yi-Bo Feng, Tongde Hospital of Zhejiang Province and the voucher specimens (SYSQC20151001) was deposited at the Key Laboratory of Research and Development of Chinese Medicine of Zhejiang Province, Zhejiang Academy of Traditional Chinese Medicine.

\section{Preparation of plant extracts}

The dried G. pensylvanicum (500 g) was extracted using $10 \mathrm{~L} 95 \%(v / \mathrm{v})$ ethanol for 3 times $(3 \times 60 \mathrm{~min})$ by heat reflux extraction. Then solvents were removed with vacuum rotary evaporation to yield $34.38 \mathrm{~g}$ of residue. The extraction yield of G. pensylvanicum was $6.88 \%(w /$ w) which was kept at $-20{ }^{\circ} \mathrm{C}$ until used.

\section{UPLC-ESI-MS/MS analysis of G. pensylvanicum Sample preparation}

The G. pensylvanicum extracts were prepared by ultrasonic extraction of $1.0 \mathrm{~g}$ of powdered dried plant material in $20 \mathrm{~mL}$ methanol for $1.5 \mathrm{~h}$ at room temperature. The extract was filtered and evaporated in a rotary evaporator. The final extracts were dissolved with $2.0 \mathrm{~mL}$ and filtered through a $0.25 \mathrm{~mm}$ fluorpore membrane (Millipore, MA, USA) prior to injection into the UPLC-ESI-MS/MS system.

\section{UPLC-ESI-MS/MS analyses}

The Acquity Ultra Performance LC-system (Waters, Milford, MA) with TQ detector was employed to analyses. The UPLC analyses were performed using an Acquity UPLC BEH column $(2.1 \times 100 \mathrm{~mm}$ i.d., $1.7 \mu \mathrm{m})$ with a binary mobile phase. Solvetn A was $0.1 \%$ formic acid aqueous and $\mathrm{B}$ was acetonitrile. 
The gradient elution at room temperature was as 15$60 \%(\mathrm{v} / \mathrm{v}) \mathrm{B}$ at $15 \mathrm{~min}$. The flow rate was $0.25 \mathrm{~mL} / \mathrm{min}$ and the sample volume injected was $1 \mu \mathrm{L}$. The detection wavelength was $250 \mathrm{~nm}$. LC-MS analysis was carried out using a Waters TQ Detector equipped with electrospray ionization (ESI) source. The MS was operated in negative mode, and the data were acquired in scan mode using a $m / z$ range of 150 to 1000 . The data acquisition and analyses was carried out with Masslynx Workstation Software (version 4.1.896).

\section{Preparation of drugs and test solutions for in vivo methods}

All solution and potassium oxonate suspension were prepared dependent on the medium weight of each group. Allopurinol (4 mg/mL), colchicine $(100 \mathrm{mg} / \mathrm{L})$, low content G. pensylvanicum (LGP) $(20 \mathrm{mg} / \mathrm{mL})$, middle content G. pensylvanicum (MGP) $(40 \mathrm{mg} / \mathrm{mL})$ and high content G. pensylvanicum (HGP) $(80 \mathrm{mg} / \mathrm{mL})$ were solubilized in $0.5 \%$ DMSO and physiological saline. Potassium oxonate was prepared in suspension with $0.9 \% \mathrm{NaCl}$ solution (30 mg/mL). Monosodium urate crystals were suspended in $0.9 \%$ sterile saline $(25 \mathrm{mg} /$ $\mathrm{mL}$ ) and twain 80.

\section{Experimental animals}

60 male Kun-Ming mice $(18 \sim 22 \mathrm{~g})$ and 60 male ICR mice $(18 \sim 22 \mathrm{~g})$ were obtained from Experimental Animal Center of Zhejiang Academy of Medical sciences. Animals were housed in plastic cages and maintained on a 12/12 h light/dark cycle and had free access to standard pellet diet and tap water. All experimental procedures were approved by the Guidance Suggestions for the Care and Use of Experimental Animals in Zhejiang University.

\section{Models of hyperuricemia and drug treatment}

Uricase inhibitor PO was used to induce the hyperuricemia model in mice, as described previously. Sixty male Kun-Ming mice were divided into six groups: blank, model, allopurinol (40 mg/kg/day), and the GPE (100, 200 and $400 \mathrm{mg} / \mathrm{kg} /$ day) groups. The GPE and allopurinol were given continuously every $24 \mathrm{~h}$ six days before hyperuricemia was induced. Normal saline was given to the blank group. The dosages of the GPE were based on the effective dosages in the clinic [9]. Mice were injected intraperitoneally with PO $(300 \mathrm{mg} / \mathrm{kg})$ to induce hyperuricemia one hour after the last intragastric administration of GPE and allopurinol on the 7th day.

\section{Models of acute gouty arthritis and drug treatment}

The model of acute gouty arthritis was induced by hypodermic injection of $0.1 \mathrm{~mL}(10 \mathrm{mg})$ of $\mathrm{MSU}$ crystal suspension into the right foot pad. The male
ICR mice were divided into 6 groups, and each group including 10 animals. They were blank, model, colchicine (1 mg/kg/day), the GPE (100, 200 and $400 \mathrm{mg} / \mathrm{kg} /$ day) groups. Drugs were intragastricly feed once daily for 7 days. On the 7 th day, the MSU crystal was injected $1 \mathrm{~h}$ later after drugs were given. Drugs continued to be given for 1 day after injection of MSU crystal. Paw swelling was expressed as thickness variation. Paw thickness was measured with digital display micrometer gauge (Shanghai ChuanLu Measuring Tool Co., Ltd) at 0, 1, 4, 12 and $24 \mathrm{~h}$ after MSU injection. All doses were expressed as mg per $\mathrm{kg}$ body weight of the respective drugs.

\section{Blood and tissue processing \\ Models of hyperuricemia}

On the 7 th day, $1 \mathrm{~h}$ after final administration, blood samples were collected and allowed to clot for $1 \mathrm{~h}$ at room temperature, and centrifuged at $3000 \mathrm{rpm}$ for $10 \mathrm{~min}$ to obtain serum. Serum samples were used for the estimation of uric acid level and stored at $-20{ }^{\circ} \mathrm{C}$ until testing. The liver tissues were also dissected quickly on an ice-plate for the XO assay. The renal were cut into tubes for histological and western blotting analysis. All the samples were frozen at $-80^{\circ}$ $\mathrm{C}$ until used for assays.

\section{Models of acute gouty arthritis}

Blood samples were collected $24 \mathrm{~h}$ after MSU injection and allowed to clot for approximately $1 \mathrm{~h}$ at room temperature and then centrifuged to obtain the serum. Serum samples were stored at $-20{ }^{\circ} \mathrm{C}$ until testing for cytokines levels were assayed. The mice were then sacrificed and paw surrounding tissues were collected for histological analyses and frozen at $-80{ }^{\circ} \mathrm{C}$.

\section{Uricosuric activity in mice}

Sur was measured by the enzymatic colorimetric method using a standard diagnostic kit (Jiancheng, Nanjing), according to manufacturer's instructions.

\section{Assays inhibition of liver XO activity}

The livers were homogenized in ice-cold saline (9 volumes), then centrifuged at $8000 \mathrm{rpm}$ for $10 \mathrm{~min}$ at $4{ }^{\circ} \mathrm{C}$. After centrifugation, the lipid layer was carefully removed and the final supernatant fraction was used for XO activity assays. The XO activity in liver was determined using a standard diagnostic kits (Jiancheng, Nanjing). The liver XO enzyme activity is expressed as $\mathrm{mol} / \mathrm{min}$ per $\mathrm{g}$ protein $(\mathrm{U} / \mathrm{g})$. 


\section{Western blotting analysis of mGLUT9, mOAT1 and mURAT1 in kidney tissues}

Total protein was obtained from the renal using the Tissue Protein Extraction Kit (KeyGEN Biotech. CO., Ltd., China). Briefly, kidney were collected and lysed in appropriate cold lysis buffer contained $1 \mathrm{mM}$ phenylmethylsulfonyl fluoride (PMSF). After centrifugation $\left(15,000 \mathrm{~g}\right.$ for $15 \mathrm{~min}$ at $\left.4{ }^{\circ} \mathrm{C}\right)$, the total protein was obtained in the supernatant. The protein level was quantified of the BCA protein assay kit (Tiangen Biotech Co., Ltd., China), according to the manufacturer's instructions. Protein sample $(7 \mathrm{mg} / \mathrm{mL})$ was denatured by mixing with an equal volume of 2 sample loading buffer, and boiling at $100{ }^{\circ} \mathrm{C}$ for $5 \mathrm{~min}$. Samples were resolved by electrophoresis with $10 \%$ SDS-PAGE and transferred onto a PVDF membrane (Merk, Germany). After blocking non-specific binding sites for $3 \mathrm{~h}$ with $5 \%$ dried skim milk dissolved in PBST (0.05\% Tween 20), the membranes were individually incubated for overnight with anti-URAT (1:500 dilution), anti-GLUT9 (1:500 dilution), antiOAT1 (1:500 dilution) as well as anti- $\beta$-actin (1:500 dilution). Develop the color of the blot rocking in 3, 3 '-diaminobenzidine (DAB) substrate solution. Stop the reaction by pouring out the substrate after the expected band appears, then well rinsed with distilled water repeatedly. Dry the membrane and store it in the dark place. The data were analyzed via densitometry using Molecular Analyst software (Bio-Rad Laboratories, Hercules, CA) and quantitated levels were normalized to their respective blotting from $\beta$-actin.

\section{Assessment of paw swelling}

The inflammation was quantified by measuring the thickness of the paw at $0,1,4,12$ and $24 \mathrm{~h}$ after MSU crystal injections.

\section{Cytokines assay}

The levels of IL- $1 \beta$ and TNF- $\alpha$ in the serum were determined using ELISA kits (Assay, R\&D Systems), according to manufacturer's instructions.

\section{Histological analyses \\ Models of hyperuricemia}

Mice's kidneys were fixed for $24 \mathrm{~h}$ at room temperature in $4 \%$ form paraformaldehyde. Paraffin sections $(4 \mu \mathrm{m}$ thick) were prepared from each kidney, stained with hematoxylin and eosin ( $\mathrm{H} \& \mathrm{E})$ and examined under light miscroscope (Eclipse TI-SR, Nikon Instruments Inc., Japan) at a $200 \times$ magnification.

\section{Models of acute gouty arthritis}

The paw region of MSU induced gouty arthritis mice was isolated and decalcified in $10 \%$ formaldehyde solution, embedded in paraffin and sectioned at $5 \mu \mathrm{m}$, followed by staining with $\mathrm{H}$ \& $\mathrm{E}$ and examined under the light microscope at a $200 \times$ magnification.

\section{Statistical analysis}

All results were expressed as the mean \pm standard error of the mean (SEM). The one-way analysis of variance (ANOVA) was used to determine the level of significance followed by using GraphPad Prism 5.0 Software (GraphPad Software, San Diego, CA, USA).

\section{Results}

Screening of chemical compounds in the $G$. pensylvanicum

The base peak chromatogram that resulted for the GPE is depicted in Fig. 1, where the peaks are numbered according to their elution order. Totally 14 metabolites present in G. pensylvanicum were identified by interpretation of their DAD, MS and MS/MS spectra found by UPLC-ESI-MS/MS (Table 1) combined with the data provided in the literature [18-22]. The analysis of the methanol extract revealed that caffeoylquinic acid derivatives were the major classes of secondary metabolites in G. pensylvanicum.

\section{Effects of G. pensylvanicum on uric acid levels in serum} As shown in Table 2, compared with blank group $(5606.7 \pm 1564.9 \mu \mathrm{mol} / \mathrm{L})$, uric acid level of serum in model group mice $(10,675.5 \pm 3423.7 \mu \mathrm{mol} / \mathrm{L})$ was significantly increased after PO administration. Allopurinol, as a positive control drug, significantly reduced uric acid level of serum compared with model group mice $(p<0.01)$. All doses of G. pensylvanicum markedly decreased uric acid level a dosedependent, compared with model group mice. Meanwhile, as shown in Fig. 2, all doses of G. pensylvanicum used in this study did not significant effect weight compared with blank group mice. But in the allopurinol group the allopurinol significantly inhibited the weight growth.

\section{Effect of G. pensylvanicum on XO activity in liver}

As shown in Table 2, PO administration induced a significant advancement of $\mathrm{XO}$ activity in liver of model group mice compared with blank group mice $(p<0.01)$. Allopurinol significantly attenuated the XO activity in liver $(5.34 \pm 0.65 \mathrm{U} / \mathrm{g})$ of hyperuricemia mice model $(54.28 \pm 8.17 \mathrm{U} / \mathrm{g})$. GPE also significantly exhibited a dose-dependent $\mathrm{XO}$ activity in liver of hyperuricemia mice model. 


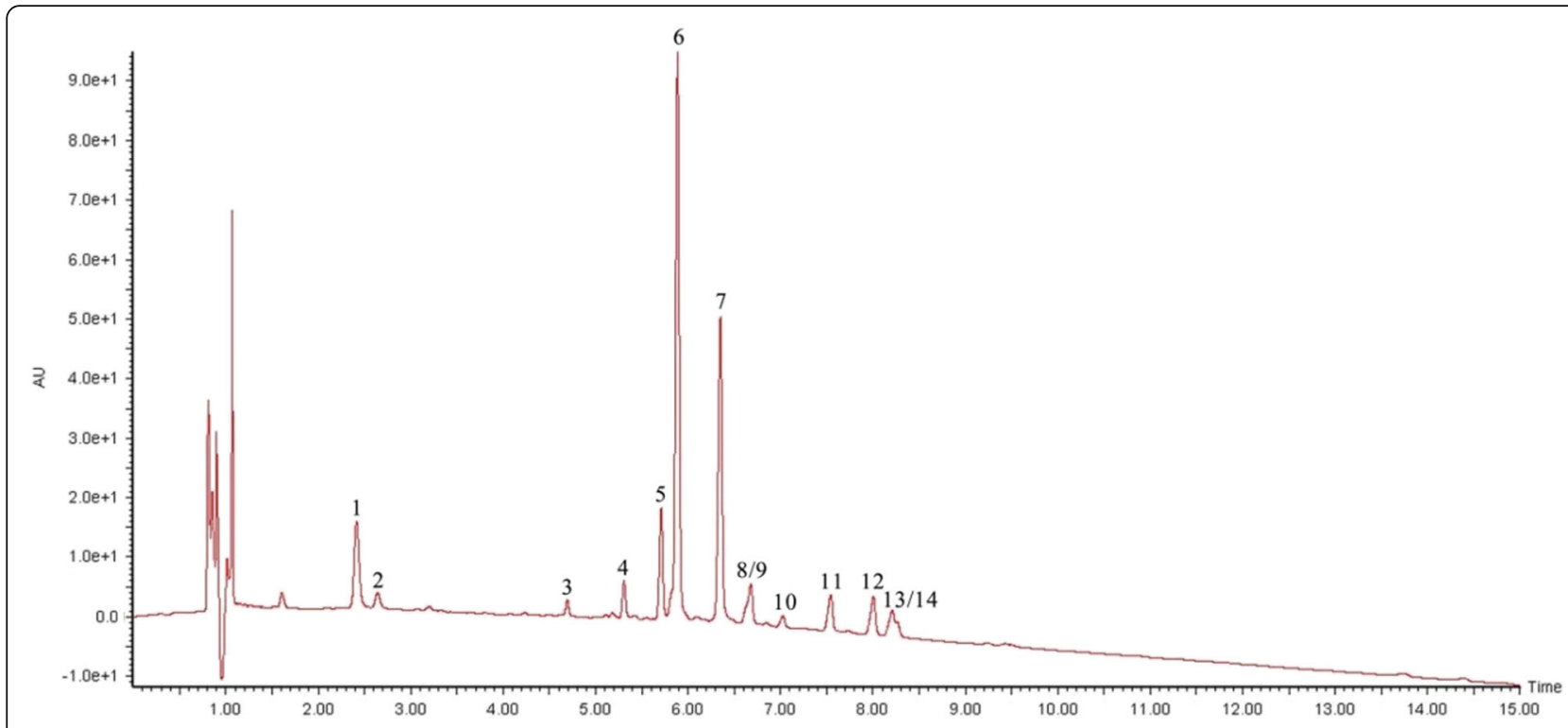

Fig. 1 Base peak chromatogram of G. pensylvanicum extract by UPLC-ESI-MS/MS in the negative ion mode. Peak labelling represents the compounds identified

Effects of G. pensylvanicum on expressions of mGLUT9, mURAT1 and mOAT1 in kidney

As shown in Fig. 3, compared with blank group, PO administration induced a significant down-regulation of the mOAT1 protein expressions in mice kidney, as well as a significant up-regulation of the mGLUT9 and mURATl protein expression. All doses of G. pensylvanicum significantly inhibited the mURATl and mGLUT9 protein expression, and $400 \mathrm{mg} / \mathrm{kg}$ G. pensylvanicum significantly elevated the mOAT1 protein expressions in hyperuricemia mice kidney, respectively, compared with model group. Allopurinol, could also regulated the expression levels of renal mGLUT9, mOAT1 and mURAT1 protein in hyperuricemia mice compared with model group as showed in Fig. 3.

\section{Effect of G. pensylvanicum on improving renal dysfunction}

As results above, levels of Sur could be restored by all doses of G. pensylvanicum in hyperuricemia mice. Our histological data support the observations of uric acid level changes after treatment, and is consistent with the

Table 1 Proposed compounds detected in G. pensylvanicum obtained by UPLC-ESI- MS/MS

\begin{tabular}{|c|c|c|c|c|c|c|}
\hline Peak & Rt (min) & $\begin{array}{l}\text { UV } \\
\lambda_{\max }(\mathrm{nm})\end{array}$ & $m / z$ & MS/MS fragments & Proposed compound & Reference \\
\hline 1 & 2.41 & $213.7,325.7$ & 352.9 & 146.1 & 3-caffeoylquinic acid & [18-22] \\
\hline 2 & 2.64 & 322.7 & 352.9 & 249.2 & 4-caffeoylquinic acid & [18-21] \\
\hline 3 & 4.69 & $235.7,325.7$ & 367.0 & $308.9,201.9,175.3$ & feruloylquinic acid & {$[20,21]$} \\
\hline 4 & 5.31 & $252.7,345.7$ & 447.1 & $435.7,293.5,106.6$ & |uteolin-7-O-glucoside & {$[22]$} \\
\hline 5 & 5.71 & $219.7,242.7,324.7$ & 515.2 & $428.8,334.7,94.9$ & 1, 3-di-caffeoylquinic acid & [19-21] \\
\hline 6 & 5.89 & $218.7,242.7,326.7$ & 515.3 & $490.9,352.0,179.1$ & 1, 4-di-caffeoylquinic acid & {$[19,20]$} \\
\hline 7 & 6.34 & $218.7,243.7,326.7$ & 515.2 & $352.9,173.0$ & 3, 4-di-caffeoylquinic acid & [18-21] \\
\hline 8 & 6.61 & $244.7,326.7$ & 515.2 & $434.1,346.3,178.8$ & 4, 5-di-caffeoylquinic acid & [18-21] \\
\hline 9 & 6.68 & $243.7,327.7$ & 601.0 & $288.4,240.9$ & 3-methoxyoxaloyl-1, 5-di-caffeoylquinic acid & {$[22]$} \\
\hline 10 & 7.03 & $243.7,325.7$ & 528.7 & $367.4,172.8,149.0$ & 1-caffeoyl-3-feruloylquinic acid & [21] \\
\hline 11 & 7.54 & $243.7,326.7$ & 529.2 & $362.7,349.2,179.2$ & 4-caffeoyl-3-feruloylquinic acid & {$[18,21]$} \\
\hline 12 & 8.01 & $244.7,328.7$ & 529.0 & $374.0,179.0,155.6$ & 4-caffeoyl-5-feruloylquinic acid & {$[18,21]$} \\
\hline 13 & 8.21 & $243.7,327.7$ & 557.0 & $395.4,233.3,173.0$ & acetyldi-caffoylquinic acids & {$[22]$} \\
\hline 14 & 8.26 & $243.7,326.7$ & 615.4 & $453.5,360.9,235.8$ & succinoyl dicaffeoylquinic acids & [20] \\
\hline
\end{tabular}


Table 2 Effects of G. pensylvanicum and Allopurinol on Sur and XO active in Liver of PO-Induced Hyperuricemic Mice

\begin{tabular}{llll}
\hline Groups & Dose $(\mathbf{m g} / \mathbf{k g})$ & Sur( $\mu \mathrm{mol} / \mathbf{L})$ & Liver XO (U/g protein) \\
\hline Blank & - & $5606.7 \pm 1564.9$ & $11.14 \pm 1.06$ \\
Model & - & $10,675.5 \pm 3423.7^{* *}$ & $54.28 \pm 8.17^{\# \#}$ \\
Allopurinol & 40 & $4280.1 \pm 2229.5^{\# \#}$ & $5.34 \pm 0.65^{* *}$ \\
G. pensylvanicum extract & 100 & $8388.6 \pm 1546.3^{* *}$ & $10.85 \pm 1.53^{* *}$ \\
& 200 & $7288.3 \pm 4615.0^{* *}$ & $8.48 \pm 0.85^{* *}$ \\
& 400 & $6012.9 \pm 783.6^{* *}$ & $6.09 \pm 0.45^{* *}$ \\
\hline
\end{tabular}

Data represent mean \pm SEM for 10 mice; ${ }^{\#} p<0.05,{ }^{\# \#} p<0.01$ compared with Blank group (independent samples t-test); ${ }^{*} p<0.05,{ }^{* * *} p<0.01$ compared with Model group

Sur observations in hyperuricemia mice model. Histological examination of renal tissue from the normal mice (Fig. 4a) showed normal renal architecture. Histological analyses showed that the renal tubules were shrank in the model mice (Fig. 4b), compared with the normal mice. These pathological states were ameliorated in some degree by treating with G. pensylvanicum (Fig. 4.). However, it is worth noting that allopurinol treatment induced the surface of kidney in allopurinol group showed white were different from the other groups. These results suggested that allopurinol may have the renal toxicity. These results suggested that allopurinol may have the renal toxicity.

\section{Effects of G. pensylvanicum on the MSU crystal-induced mice}

MSU crystals injection caused a significant increase in paw swelling compared with the model group. As shown in Fig. 5 , the paw volume of MSU-induced mice revealed an increase in ankle diameter, whereas G. pensylvanicum (100,
200, and $400 \mathrm{mg} / \mathrm{kg}$ ) and colchicine $(1 \mathrm{mg} / \mathrm{kg})$ treatment decreases the paw diameter significantly in MSU crystalinduced mice.

Joints synovial and surrounding tissues were obtained from the knee joint 2 days after the MSU injection. In the blank control group showed normal and no inflammatory cell infiltration. Model group showed apparent joint inflammation, a number of inflammatory cells infiltration, and hyperplasia synovial. These pathological states were ameliorated in some degree by treating with colchicine and G. pensylvanicum dose (Fig. 6). The results demonstrated that G. pensylvanicum and colchicine could improve the symptoms of MSU crystal-induced mice, and they could decrease the infiltration of inflammatory cells.

Effects of $G$. pensylvanicum extracts on the levels of IL-1 $\beta$ and TNF- $a$ in MSU crystal-induced mice

To investigate the mechanism of G. pensylvanicum in the improvement of paw swelling of MSU crystal-induced mice, the levels of two pro-inflammatory cytokines in the serum

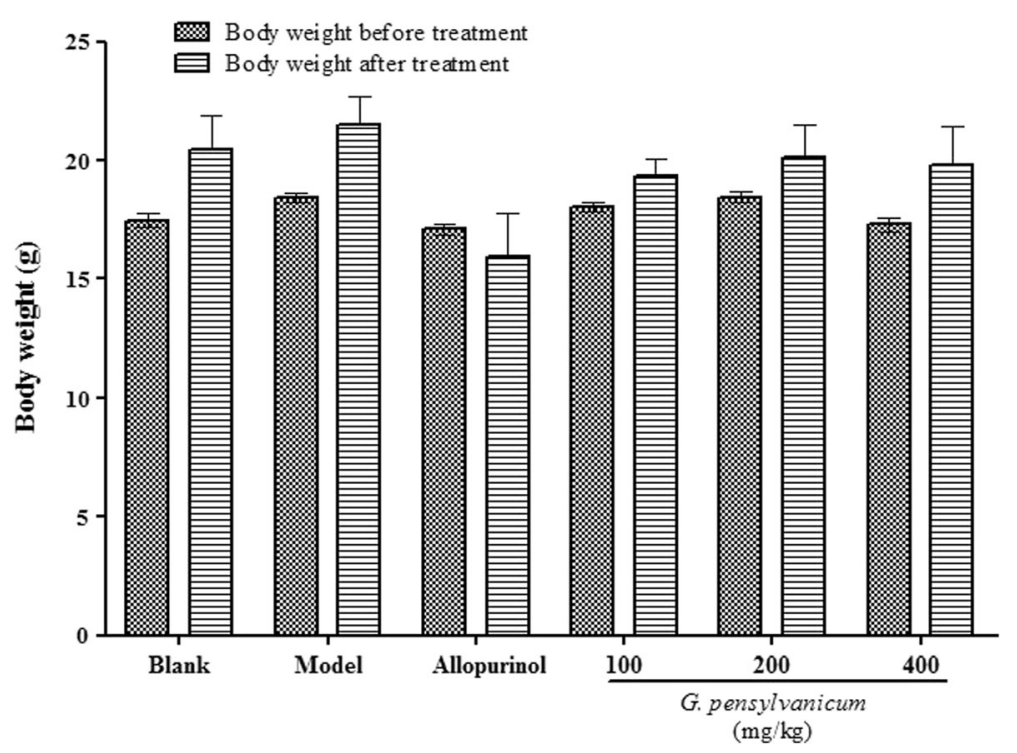

Fig. 2 Effects of G. pensylvanicum on body weights of hyperuricemia mice. Data are expressed as mean $\pm \operatorname{SEM}(n=10)$ 

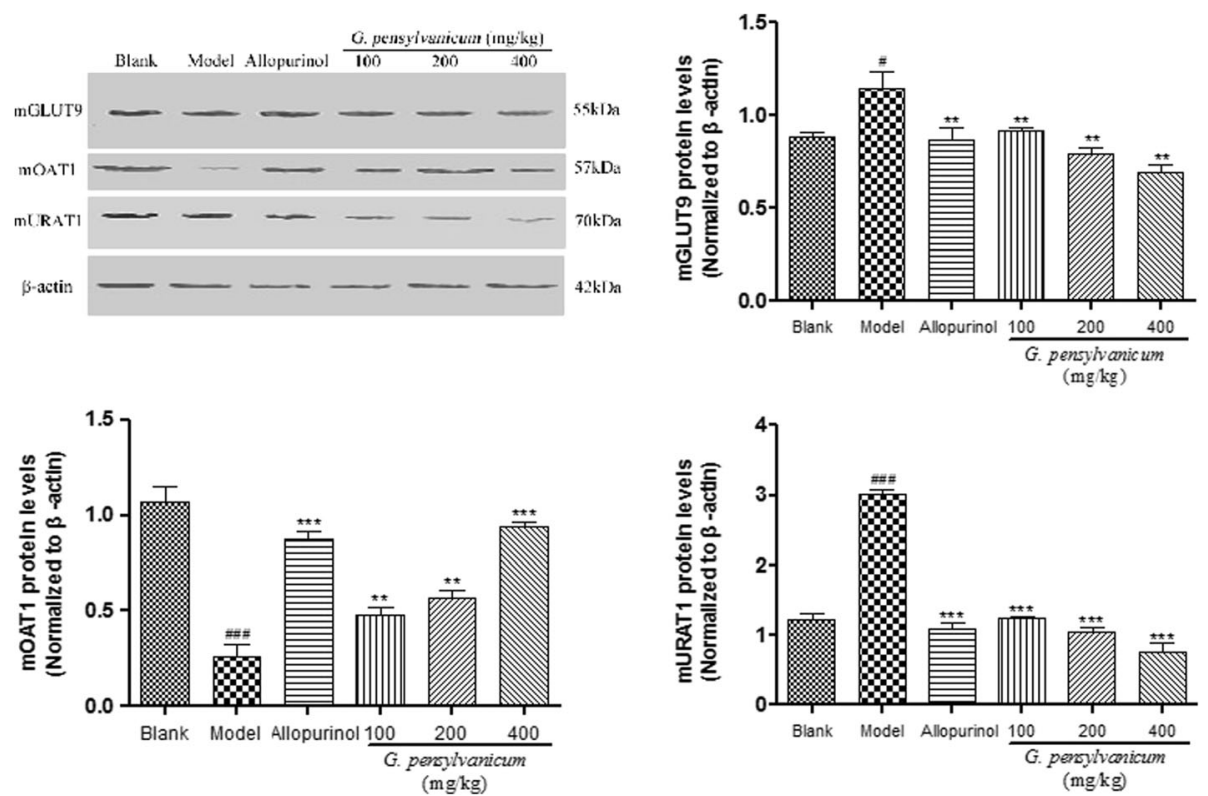

Fig. 3 Effects of G. pensylvanicum and Allopurinol on protein expression of mGLUT9, mOAT1 and mURAT1 in renal tissues in hyperuricemia mice by Western blot analysis. $N=10$ per group. ${ }^{\# \#} p<0.01,{ }^{\# \#} p<0.001$ compare with blank; ${ }^{* *} p<0.01,{ }^{* * *} p<0.001$ compare with model

were determined. As shown in Fig. 7, MSU crystal induced a significant increase of TNF- $\alpha$ and IL- $1 \beta$ levels in serum $(p<0.01, p<0.01$, respectively.). Post-hoc analysis indicated that G. pensylvanicum extracts decreased TNF- $\alpha(100,200$, $400 \mathrm{mg} / \mathrm{kg}: p<0.01)$ and IL-1 $\beta(100 \mathrm{mg} / \mathrm{kg}: p<0.05 ; 200$ $\mathrm{mg} / \mathrm{kg}: p<0.05 ; 400 \mathrm{mg} / \mathrm{kg}: p<0.01$, respectively.) levels. In addition, the positive drug colchicine $(1 \mathrm{mg} / \mathrm{kg})$ also reduced the TNF- $\alpha$ and IL- $1 \beta$ levels in serum $(p<0.01, p<0.01$, respectively.) compared to the model group.

\section{Discussion}

Hyperuricemia is a disorder of uric acid metabolism disease associated with the development of pathological conditions such as gout. Although the disease afflicts humans for years, there were a limited number of drugs currently used in clinical for treating, but there are side effects associated with its use [23, 24]. Natural plant products were the most popular source of complementary and alternative medicines for novel antihyperuricemia agents [25].

Gout is a form of inflammatory arthritis characterized by recurrent attacks. And then inflammation is one of the major problems of gout patients has been evaluated [26]. It is well accepted that proinflammatory cytokines such as TNF- $\alpha$ and IL- $1 \beta$ help to propagate the extension of a local or systemic
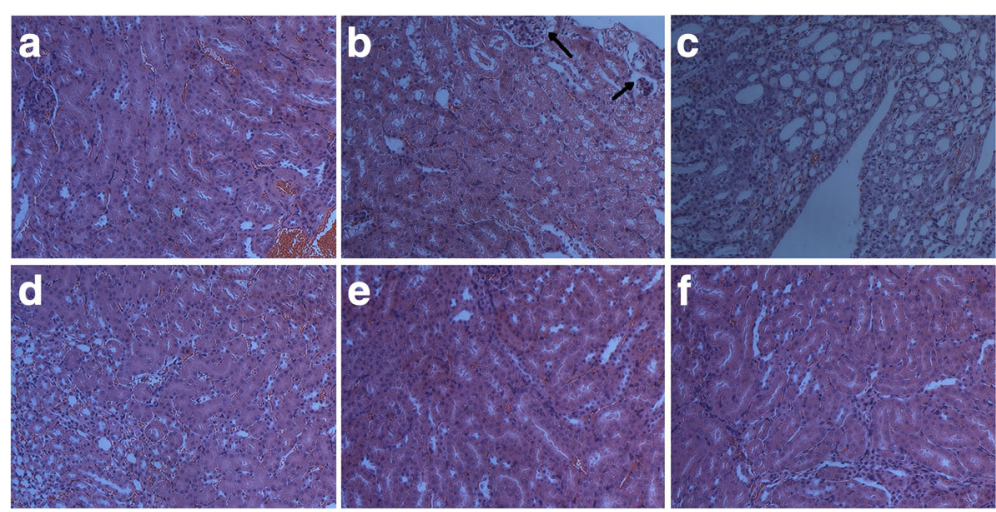

Fig. 4 Histology of the kidney, H \& E Stain, 200x. (a) Blank group, (b) Model group with PO, (c) Allopurinol 40 mg/kg, (d) G. pensy/vanicum $100 \mathrm{mg} / \mathrm{kg}$, (e) G. pensylvanicum $200 \mathrm{mg} / \mathrm{kg}$ and (f) G. pensylvanicum $400 \mathrm{mg} / \mathrm{kg}$ 


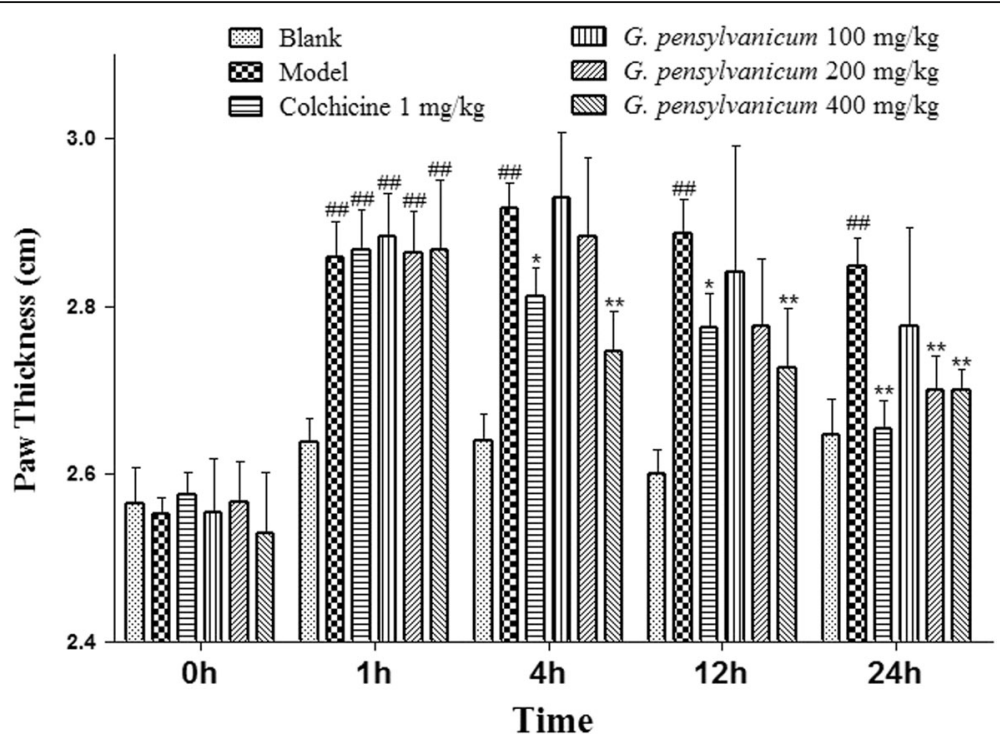

Fig. 5 Effect of G. pensylvanicum and colchicine on MSU crystal-induced paw edema in mice. Data are expressed as mean $\pm \operatorname{SEM}(n=10)$. $\# p<0.01$ compare with Blank group; ${ }^{* *} p<0.01,{ }^{*} p<0.05$ compare with Model group

inflammatory process [27]. So, anti-inflammatory was considered as the main method for the treatment of gout.

In this study, G. pensylvanicum extracts were able to inhibit the residual activity of xanthine oxidase in vivo and improvement MSU crystal-induced mice paw swelling. Meanwhile, administration of the G. pensylvanicum extracts caused a reduction in Sur level in hyperuricemia mice by regulating the abnormal expression levels of mURAT1, mOAT1 and mGLUT9. Thus, G. pensylvanicum extracts were able to reduce hyperuricemia and against gouty arthritis through these pathways: increasing uric acid excretion, inhibiting xanthine oxidase activity and pro-inflammatory cytokines secretion, indicating that G. pensylvanicum may represent efficacy in the treatment of hyperuricemia and gout. In addition, G. pensylvanicum extracts showed renal protection which different from the allopurinol has renal toxicity.

In the phytochemical investigations of G. pensylvanicum resulted suggested this plant was rich in caffeoylquinic acid derivatives. Among these compounds, chlorogenic acid [13], 3,5-dicaffeoylquinic acid [11], 4,5-dicaffeoylquinic acid methyl ester [10] and 1,5dicaffeoylquinic acid [12] showed significant inhibition of xanthine oxidase activity and anti-hyperuricemia. Thus, anti-hyperuricemia effects by uricosuric or inhibition of xanthine oxidase way by the G. pensylvanicum extracts can be partially attributed to

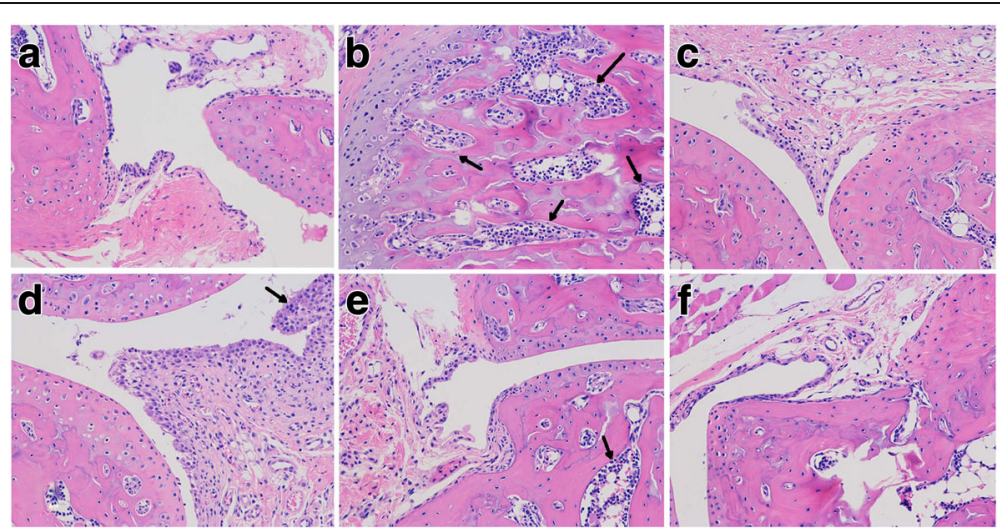

Fig. 6 Effects of G. pensylvanicum on pathological changes in paw surrounding tissue of mice. All sections were stained with $\mathrm{H}$ \& $\mathrm{E}$ Stain (magnification A-F, ×200). a Blank group, (b) Model group with MSU, (c) Colchicine $1 \mathrm{mg} / \mathrm{kg}$, (d) G. pensylvanicum $100 \mathrm{mg} / \mathrm{kg}$, (e) G. pensylvanicum $200 \mathrm{mg} / \mathrm{kg}$ and (f) G. pensylvanicum $400 \mathrm{mg} / \mathrm{kg}$ 

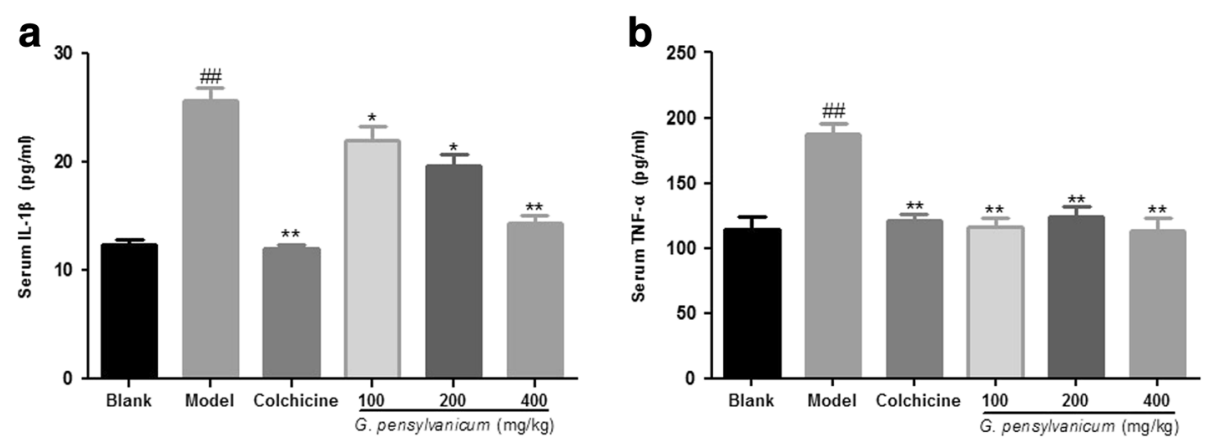

Fig. 7 Effects of G. pensylvanicum and colchicine on the levels of IL-1 $\beta$ (a), and TNF- $\alpha(\mathbf{b})$ in the serum were measured $24 \mathrm{~h}$ after hypodermic injection of MSU crystals. Results were shown as mean \pm SEM $(n=10) .{ }^{\# \#} p<0.01$ vs. Blank group; $p<0.05,{ }^{* *} p<0.01$ vs. Model group

caffeoylquinic acid derivatives. It could also effectively regulate PO-induced changes of renal mURAT1, mGLUT9 and mOAT1 expressions, resulting in the enhancement of uric acid excretion. However, further investigation is needed to evaluate potential clinical using of G. pensylvanicum and its bioactive components. These insights are relevant to further develop the new drugs from $G$. pensylvanicum for the treatment of gouty.

\section{Conclusions}

The present results clearly demonstrated that the $G$. pensylvanicum showed remarkable anti-hyperuricemia and anti-gouty arthritis activity. The tested extract possesses potent uricosuric effect in hyperuricemia mice through effect renal mGLUT9, mOAT1 and mURAT1 mainly and inhibiting XO activity in a certain extent, which are attributable to the enhancement of uric acid excretion and protect hyperuricemia-induced renal dysfunction. This beneficial anti-gouty arthritis effect may be mediated, at least in part, by inhibiting the production of IL- $1 \beta$ and TNF- $\alpha$. Meanwhile, the caffeoylquinic acid derivatives were identified by UPLC-ESI-MS/ MS as the main active ingredients of G. pensylvanicum. Therefore, G. pensylvanicum extracts can be considered promising in the treatment of diseases like hyperuricemia and gout. The safety and potential clinical utility of the $G$. pensylvanicum in the uric acid excretion and renal dysfunction reduction needs to be confirmed and evaluate by future studies. In addition, the active contents of $G$. pensylvanicum are engaged to explain.

\footnotetext{
Abbreviations

ANOVA: Analysis of variance; BCA: Bicinchoninic acid; ELISA: Enzyme-linked immunosorbent assay; GLUT9: Glucose transporter 9; GPE: Gnaphalium pensylvanicum extract; $\mathrm{H}$ \& E: Hematoxylin and eosin; HGP: High content of G. pensylvanicum extract; IL-1 $\beta$ : Interleukin-1 $\beta$; LGP: Low content of G. pensylvanicum extract; MGP: Middle content of G. pensylvanicum extract; MSU: Monosodium urate; OAT1: Organic anion transporter 1; PMSF: Phenylmethylsulfonyl fluoride; PO: Potassium oxonate;

PVDF: Polyvinylidene fluoride; SEM: Standard error of the mean; Sur: Serum
}

levels of uric acid; TNF- $a$ : Tumor necrosis factor- $a$; UA: Uric acid; URAT1: Urate transporter 1: XO: Xanthine oxidase

\section{Acknowledgments}

The present study was supported by Key Laboratory of Research and Development of Chinese Medicine of Zhejiang Province, Zhejiang Institute of Traditional Chinese Medicine for providing all the necessary facilities to carry out this work

\section{Funding}

This work was financially supported by the Program of Zhejiang Provincial Department of Science and Technology (2016C31001), Project of Administration of Traditional Chinese Medicine of Zhejiang Province (2A21624).

\section{Availability of data and materials}

The datasets supporting the conclusions of this article are presented in this main paper. Plant material used in this study was identified at Tongde Hospital of Zhejiang Province and voucher specimens are deposited at the Key Laboratory of Research and Development of Chinese Medicine of Zhejiang Province, Zhejiang Academy of Traditional Chinese Medicine.

\section{Authors' contributions}

HJZ designed the experiments, and was a major contributor in writing the manuscript. YJ, YL and YJH carried out the laboratory experiments. XJS and HHP analyzed the data, interpreted the results and prepared figures. All authors read and approved the final manuscript.

\section{Competing interests}

The authors declare that they have no competing interests.

\section{Consent for publication}

Not applicable.

\section{Ethics approval}

All animal studies were performed using protocols approved by the Animal Care and Use Committee of Zhejiang University.

\section{Publisher's Note}

Springer Nature remains neutral with regard to jurisdictional claims in published maps and institutional affiliations.

\section{Author details}

${ }^{1}$ Dispensary of Traditional Chinese Medicine, Hangzhou First People's Hospital, 261 Huansha Road, Hangzhou 310006, China. 'Department of Pharmacy, Tongde Hospital of Zhejiang Province, 234 Gucui Road, Hangzhou 310012, China. ${ }^{3}$ Key Laboratory of Research and Development of Chinese Medicine of Zhejiang Province, Zhejiang Academy of Traditional Chinese Medicine, 132 Tianmushan Road, Hangzhou 310007, China. 
Received: 28 March 2017 Accepted: 8 June 2017

Published online: 17 June 2017

\section{References}

1. Nuki G, Simkin PA. A concise history of gout and hyperuricemia and their treatment. Arthritis Research \& Therapy. 2006;8:S1.

2. Hou CW, Lee YC, Hung HF, Fu HW, Jeng KC. Longan seed extract reduces hyperuricemia via modulating urate transporters and suppressing xanthine oxidase activity. The American journal of Chinese medicine. 2012;40:979-91.

3. Zhao $\mathrm{R}, \mathrm{Chen} \mathrm{D}, \mathrm{Wu} \mathrm{H}$. Pu-erh ripened tea resists to hyperuricemia through xanthine oxidase and renal urate transporters in hyperuricemic mice. J Funct Foods. 2017;29:201-7.

4. Martinon F. Mechanisms of uric acid crystal-mediated autoinflammation. Immunol Rev. 2010;233:218-32.

5. Enomoto A, Endou H. Roles of organic anion transporters (OATs) and a urate transporter (URAT1) in the pathophysiology of human disease. Clin Exp Nephrol. 2005;9:195-205.

6. Wu XH, Ruan JL, Zhang J, Wang SQ, Zhang YW. Pallidifloside D, a saponin glycoside constituent from Smilax Riparia, resist to hyperuricemia based on URAT1 and GLUT9 in hyperuricemic mice. J Ethnopharmacol. 2014;157:201-5.

7. Hu QH, Zhu JX, Ji J, Wei LL, Miao MX, Ji H. Fructus gardenia extract ameliorates oxonate-induced hyperuricemia with renal dysfunction in mice by regulating organic ion transporters and mOIT3. Molecules. 2013;18:8976-93.

8. Clive DM. Renal transplant-associated hyperuricemia and gout. J Am Soc Nephrol. 2000;11:974-9.

9. Chinese medicinal materials company. Traditional Chinese Medicine Resources of China. Science press; 1994.

10. Nguyen MTT, Awale S, Tezuka Y, Shi L, Zaidi SFH, Ueda JY, et al. Hypouricemic effects of acacetin and 4, 5-O-dicaffeoylquinic acid methyl Ester on serum uric acid levels in potassium oxonate-pretreated rats. Biol Pharm Bull. 2005;28:2231-4.

11. Nguyen MTT, Awale S, Tezuka Y, Ueda JY, Quan LT, Kadota S. Xanthine oxidase inhibitors from the flowers of Chrysanthemum Sinense. Planta Med. 2006;72:46-51

12. Ho ST, Tung YT, Huang CC, Kuo CL, Lin CC, Yang SC, et al. The hypouricemic effect of Balanophora Laxiflora extracts and derived phytochemicals in hyperuricemic mice. Evid Based Complement Alternat Med. 2012;2012

13. Meng ZQ, Tang ZH, Yan YX, Guo CR, Cao L, Ding G, et al. Study on the anti-gout activity of Chlorogenic acid: improvement on hyperuricemia and gouty inflammation. The American journal of Chinese medicine. 2014:42:1471-83.

14. Lin WQ, Xie JX, Wu XM, Yang L, Wang HD. Inhibition of xanthine oxidase activity by gnaphalium affine extract. Chin Med Sci J. 2014;29:225-30.

15. Zhang HJ, Hu YJ, Xu P, Liang WQ, Zhou J, Liu PG. Cheng L. Pu JB Screening of Potential Xanthine Oxidase Inhibitors in Gnaphalium hypoleucum DC by Immobilized Metal Affinity Chromatography and Ultrafiltration-Ultra Performance Liquid Chromatography-Mass Spectrometry Molecules. 2016:21:1242

16. Zheng X, Wang W, Piao H, Xu W, Shi H, Zhao C. The genus Gnaphalium L. (Compositae): phytochemical and pharmacological characteristics. Molecules. 2013;18:8298-318.

17. Rasool M, Varalakshmi P. Supressive effect of Withania somnifera root powder on MSU crystal-induced inflammation an in vivo in vitro study. Chem Biol Interact. 2006;164:174-80.

18. Clifford MN, Johnston KL, Knight S, Kuhnert N. Hierarchical scheme for LC-MS ${ }^{n}$ identification of chlorogenic acids. J Agric Food Chem. 2003;51:2900-11.

19. Clifford MN, Kirkpatrick J, Kuhnert N, Roozendaal H, Salgado PR. LC-MS ${ }^{n}$ analysis of the cis isomers of chlorogenic acids. Food Chem. 2008;106:379-85.

20. Clifford MN, Wu W, Kirkpatrick J, Kuhnert N. Profiling the Chlorogenic acids and other Caffeic acid derivatives of herbal chrysanthemum by LC-MS ${ }^{n}$. J Agric Food Chem. 2007;55:929-36.

21. Jaiswal R, Sovdat T, Vivan F, Kuhnert N. Profiling and characterization by LC-MS $^{n}$ of the chlorogenic acids and hydroxycinnamoylshikimate esters in mate (llex paraguariensis). J Agric Food Chem. 2010;58:5471-84.

22. Lin LZ, Harnly JM. Identification of the phenolic components of chrysanthemum flower (Chrysanthemum morifolium Ramat). Food Chem. 2010;120:319-26.

23. Chao J, Terkeltaub R. A critical reappraisal of allopurinol dosing, safety, and efficacy for hyperuricemia in gout. Curr Rheumatol Rep. 2009;11:135-40.

24. Lee MHH, Graham GG, Williams KM, Day RO. A benefit-risk assessment of benzbromarone in the treatment of gout. Drug Saf. 2008;31:643-65.
25. Newman DJ, Cragg GM. Natural products as sources of new drugs over the 30 years from 1981 to 2010. J Nat Prod. 2012;75:311-35.

26. Cronstein BN, Sunkureddi P. Mechanistic aspects of inflammation and clinical management of inflammation in acute gouty arthritis. Journal of clinical rheumatology: practical reports on rheumatic \& musculoskeletal diseases. 2013;19:19.

27. Petronilho F, de Souza B, Vuolo F, Benetton CAF, Streck EL, Roesler R, et al. Protective effect of gastrin-releasing peptide receptor antagonist in carrageenan-induced pleural inflammation in rats. Inflamm Res. 2010;59:783.

\section{Submit your next manuscript to BioMed Central and we will help you at every step:}

- We accept pre-submission inquiries

- Our selector tool helps you to find the most relevant journal

- We provide round the clock customer support

- Convenient online submission

- Thorough peer review

- Inclusion in PubMed and all major indexing services

- Maximum visibility for your research

Submit your manuscript at www.biomedcentral.com/submit
Biomed Central 